\title{
Animal welfare in cross-ventilated, compost-bedded pack, and naturally ventilated dairy barns in the upper Midwest
}

\author{
K. M. Lobeck, ${ }^{\star}$ M. I. Endres, ${ }^{, 1}$ E. M. Shane, ${ }^{\star}$ S. M. Godden, $\dagger$ and J. Fetrow† \\ *Department of Animal Science, and \\ †Department of Veterinary Population Medicine, University of Minnesota, St. Paul 55108
}

\begin{abstract}
The objective of this cohort study was to investigate animal welfare in 2 newer dairy housing options in the upper Midwest, cross-ventilated freestall barns (CV) and compost-bedded-pack barns (CB), compared with conventional, naturally ventilated freestall barns $(\mathrm{NV})$. The study was conducted on 18 commercial dairy farms, 6 of each housing type, in Minnesota and eastern South Dakota. The primary breed in all farms was Holstein; $1 \mathrm{CV}$ and $1 \mathrm{NV}$ herd had approximately $30 \%$ Jersey-Holstein crossbreds. All freestall herds used sand for bedding. Farms were visited 4 times (once in each season) between January and November 2008, and approximately $93 \%$ of all animals in each pen were visually scored on each visit. Outcome-based measurements of welfare (locomotion, hock lesions, body condition score, hygiene, respiration rates, mortality, and mastitis prevalence) were collected on each farm. Lameness prevalence (proportion of cows with locomotion score $\geq 3$ on a 1 to 5 scale, where $1=$ normal and $5=$ severely lame) in CB barns (4.4\%) was lower than that in NV (15.9\%) and CV (13.1\%) barns. Lameness prevalence was similar between $\mathrm{CV}$ and $\mathrm{NV}$ barns. Hock lesion prevalence (proportion of cows with a lesion score $\geq 2$ on a 1 to 3 scale, where $1=$ normal, $2=$ hair loss, and $3=$ swelling) was lower in CB barns $(3.8 \%)$ than in $\mathrm{CV}$ $(31.2 \%)$ and NV barns (23.9\%). Hygiene scores (1 to 5 scale, where $1=$ clean and $5=$ very dirty) were higher for CB (3.18) than CV (2.83) and NV (2.77) barns, with no differences between $\mathrm{CV}$ and NV barns. Body condition scores, respiration rates, mastitis prevalence, culling, and mortality rates did not differ among housing systems. The CV and NV barns were evaluated using the cow comfort index (proportion of cows lying down in a stall divided by all animals touching a stall) and the stall usage index (proportion of cows lying divided by all animals in the pen not eating). The CV barns tended to have greater cow comfort index $(85.9 \%)$ than
\end{abstract}

Received March 14, 2011.

Accepted July 4, 2011.

${ }^{1}$ Corresponding author: miendres@umn.edu the NV barns $(81.4 \%)$ and had greater stall usage index (76.8\% and $71.5 \%$, respectively). Dairy cattle housed in $\mathrm{CB}$ barns had reduced lameness and hock lesions compared with those housed in freestall barns and had no adverse associations with body condition, respiration rates, mastitis prevalence, culling, or mortality. When comparing the 2 freestall housing options, CV barns had improved cow comfort indices compared with NV barns. Although cows in CB barns had better feet and leg health, as indicated by the reduced lameness and hock lesion prevalence, acquiring bedding and managing the bedded pack could limit their use.

Key words: compost-bedded pack, cross-ventilated barn, lameness, respiration rate

\section{INTRODUCTION}

Housing can affect the welfare of dairy cattle. Increased interest in farm animal welfare by the public has fostered the need to investigate the relationship between housing options and welfare of dairy cattle. Consideration needs to be taken when designing and building housing systems to provide a welfare-friendly environment.

Outcome-based measurements such as respiration rates and locomotion, hock lesion, hygiene, and body condition scores can be used as indicators of animal welfare. Lameness, which can be assessed by locomotion scoring, has been recognized as one of the most important welfare and economic concerns in the dairy industry (Enting et al., 1997). Body condition scoring provides a visual assessment of subcutaneous body fat and nutritional status (Domecq et al., 1997). Hygiene scoring assesses the cleanliness of the animal and has been associated with somatic cell score (Reneau et al., 2005). Type of stall surface has been associated with the prevalence of hock lesions (Fulwider et al., 2007; Kielland et al., 2009). Heat stress causes behavioral changes and increases mortality risk in cattle (Cook et al., 2007; Vitali et al., 2009).

Cross-ventilated freestall $(\mathbf{C V})$ and compost-bedded pack (CB) dairy barns are newer dairy cattle housing options in the upper Midwest region of the United 
States. The first CV barn was built in North Dakota in 2005, and since then, many more barns have been built in various areas of the United States. The crossventilated barn is generally a fully enclosed facility characterized by a low roof pitch of $0.5 / 12$ and a warehouse-type structure (Smith and Harner, 2007). On the air intake side of the barn, evaporative cooling pads fill the wall and air is pulled through the pads by exhaust fans on the opposite side. Inside the barn, baffles are placed over the stalls to maintain airflow. Baffles are installed parallel to the feed alley to reduce equipment interference (Sheffield et al., 2007).

The CV barns use evaporative cooling for heat abatement during the warmer months. Evaporative cooling in tunnel-ventilated dairy facilities resulted in reduced respiration rates, lower rectal temperatures, improved pregnancy rates, reduced days open, and greater milk production compared with other heat-abatement strategies (Ryan et al., 1992; Smith et al., 2006). In addition, CV barns have a reduced footprint compared with conventional freestall barns and offer better barn environmental control, and cows walk shorter distances to the milking parlor (Harner et al., 2007). However, to our knowledge, no previous studies have investigated animal welfare in these barns.

The first CB barn was built in Minnesota in 2001 (Barberg et al., 2007a). This barn is typically built for improved cow comfort by removing the lying restrictions of standard stalls. The barn is characterized by a large, loose-housing pack area that is most commonly separated from the feed alley by a 1.2-m-high concrete wall. The pack is usually bedded with dry wood sawdust or other organic materials and tilled twice daily (Barberg et al., 2007a). Lameness prevalence in these barns was 7.8\% (Barberg et al., 2007b) compared with a lameness prevalence of $25 \%$ in freestall barns (Espejo et al., 2006) and 20\% in tie-stalls (Cook, 2003).

We undertook a study to describe both the environmental conditions (K. M. Lobeck, M. I. Endres, K. A. Janni, S. M. Godden, J. Fetrow, University of Minnesota; unpublished data) and animal welfare in CB, $\mathrm{CV}$, and naturally ventilated freestall (NV) barns. The objective of the current study was to describe animal welfare using outcome-based measurements (locomotion, body condition, hygiene, hock lesions, respiration rates, culling, mortality, and mastitis infection prevalence) in $\mathrm{CV}$ and $\mathrm{CB}$ barns compared with $\mathrm{NV}$ barns.

\section{MATERIALS AND METHODS}

This cohort study was performed on 18 commercial dairy farms in Minnesota and eastern South Dakota between January and November 2008. Only barns occupied for at least $1 \mathrm{yr}$ before the start of the study were included. This requirement limited the number of herds used to 6 of each housing type to balance the study. Few CV herds were available and willing to participate in the study when it was initiated. Dairy farms were matched as closely as possible by geographical location and herd size. The primary breed in all farms was Holstein; $1 \mathrm{CV}$ and $1 \mathrm{NV}$ herd had approximately $30 \%$ Jersey-Holstein crossbreds. To reduce variation in hock lesion and lameness prevalence, all freestall barns used deep-bedded sand stalls. In addition, freestalls were similar in size and design across facilities, with an average width of approximately $122 \mathrm{~cm}$, length of 244 $\mathrm{cm}$, and neck rail height of $122 \mathrm{~cm}$. Five of the $6 \mathrm{CB}$ barns used dry wood sawdust as the primary bedding material and 1 barn used a wheat straw by-product. All CV barns used manually driven equipment to scrape alleys. Two NV barns used a flush system and 4 barns used manually driven equipment. In the $6 \mathrm{CB}$ barns, the feed alley was scraped with manually driven equipment. Barn characteristics are shown in Table 1.

\section{Data Collection}

Farms were visited once each season for a total of 4 visits per farm during 2008. Visits during January and February were considered winter visits; April and May, spring; July and August, summer; and October and November, fall. On each visit, approximately $93 \%$ of all animals in each pen were visually scored for locomotion, body condition, hygiene, and hock lesions. Pen averages were used because we were not able to obtain individual animal identification. Cow comfort and stall usage indices were collected as described by Krawczel et al. (2008). Respiration rates were measured during the summer visit. Fifteen out of the 18 herds were on DHIA testing and on-farm records were collected when available. For 2 of the 3 herds not on DHIA testing, on-farm milk weights were used for analysis.

Animal Measurements. Cows were evaluated for lameness using a 5-point locomotion scoring method (Flower and Weary, 2006). Locomotion scores (LS) were as follows: $1=$ normal locomotion, $2=$ imperfect locomotion, 3 = lame, $4=$ moderately lame, and $5=$ severely lame. Locomotion scoring was performed by a single observer as cows were exiting the milking parlor. Lameness prevalence by pen was calculated for each visit as the number of animals with LS $\geq 3$ divided by the total number of animals scored in each pen on that day. Severe lameness prevalence was calculated as the number of animals with LS $\geq 4$ divided by the total number of animals scored in the pen on the day of visit.

Animals were scored for body condition by another observer as they exited the milking parlor using a 5 -point scale, where $1=$ emaciated and $5=$ obese 
Table 1. Characteristics of compost-bedded pack (CB), cross-ventilated freestall (CV), and naturally ventilated freestall (NV) barns in Minnesota and eastern South Dakota

\begin{tabular}{|c|c|c|c|c|c|c|}
\hline Item & \multicolumn{6}{|c|}{ Housing system } \\
\hline$\overline{\text { Cows, no. }}{ }^{1}$ & 699 & 15.6 & 5,646 & 616 & 4,718 & 397 \\
\hline DIM $^{1}$ & 201 & 131 & 190 & 133 & 192 & 130 \\
\hline Parity $^{1}$ & 2.5 & 1.6 & 2.0 & 1.1 & 2.3 & 1.4 \\
\hline Stocking density $($ cows $/$ stall $\times 100)$ & - & - & 111.6 & 19.5 & 108.6 & 19.8 \\
\hline Pack density $\left(\mathrm{m}^{2} / \mathrm{cow}\right)$ & 7.6 & 1.1 & — & - & - & - \\
\hline Stall length $(\mathrm{cm})$ & - & - & 238.8 & 12.4 & 239.6 & 11.4 \\
\hline Stall width $(\mathrm{cm})$ & - & - & 117.3 & 4.9 & 118.1 & 5.3 \\
\hline Body resting length $(\mathrm{cm})$ & - & - & 165.7 & 9.1 & 167.6 & 10.3 \\
\hline Neck rail height $(\mathrm{cm})$ & - & - & 117.3 & 3.7 & 113.5 & 10.0 \\
\hline
\end{tabular}

${ }^{1}$ Total number of cows per housing system (6 farms per system) from DHIA when available (15 farms) and from on-farm records when DHIA records were not available (3 farms).

${ }^{2}$ Did not include 3 farms that were not members of DHIA (2 in CV and 1 in NV).

(Ferguson et al. 1994). Hygiene scores were assessed by the amount of dirt on the udder and lower hind legs based on a 5 -point scale with $1=$ clean and $5=$ dirty (Reneau et al., 2005). Average body condition and hygiene scores were calculated for each pen for analysis. Hock lesions (HL) were classified as 1 = no lesion, 2 $=$ hair loss (mild lesion), and $3=$ swollen hock with or without hair loss (severe lesion). Hock lesion prevalence was calculated as $\mathrm{HL} \geq 2$ divided by the total number of animals scored in the pen on that day. Severe hock lesion prevalence was calculated as $\mathrm{HL}=3$ divided by the total number of animals scored in the pen on the day of visit. Hygiene and hock lesion scoring were performed by a third observer in the parlor before milking unit was attached.

Respiration rates were taken only during the summer visit. Seventy-five animals from the multiparous high-production pen as defined by on-farm records were randomly selected for measurement of respiration rates in the CV and NV barns. In most CB barns, only one pen was used to house all animals; therefore, 75 animals from the mixed pen were scored. Two measurements were taken during the day, including mid-afternoon. Breaths were counted by observing the movements of the flank for $30 \mathrm{~s}$ and multiplying the number by 2 for breaths per minute.

Cow Comfort and Stall Usage Indices. Cow comfort index (CCI) was calculated as the number of animals lying down in the stalls divided by total number of animals touching a stall (lying, 2 feet in a stall, or standing with all 4 feet in the stall). Stall usage index (SUI) was calculated as the number of cows lying down in the stalls divided by all animals in the pen not eating. Pens were observed at least $2 \mathrm{~h}$ before or after milking and all lactating pens were observed at least once during the day with most pens observed 2 to 3 times per visit. The CB barns were excluded from the analysis because these indices are only applicable to freestall barns.

Mastitis Infection Prevalence. Mastitis infection prevalence was calculated by the number of animals with a test $\mathrm{SCC}>200,000$ cells $/ \mathrm{mL}$ divided by the total number of animals in the pen. The test date nearest to the farm visit was used for analysis. Three farms (1 NV and 2 CV barns) did not use DHIA and were excluded from analysis.

Culling and Mortality. Culling and mortality events were collected from DHIA and on-farm records when DHIA information was not available. Producers were asked to improve recordkeeping throughout the study. One CV and $1 \mathrm{NV}$ barn were excluded from the culling and mortality analyses because of insufficient or inaccurate records. Annual mortality rates were calculated by the number of animals that died divided by average herd size. Annual herd turnover rate was calculated as the number of animals that died or were sold on the farm for the entire year divided by the average herd size. Herd turnover rate for cows less than 60 DIM was calculated as animals that left the farm (died or sold) within the first 60 DIM divided by all animals that freshened during the year.

Primary categories for culling were created from DHIA "condition affecting record" (CAR) codes because some smaller dairies did not utilize dairy management software. Sold CAR categories included dairy, low productivity, breeding, injury or sick, and mastitis. Other categories were miscellaneous reasons and not reported. The breeding category included animals that failed to conceive and animals that aborted. The injury or sick category included animals that were lame, 
injured, or had metabolic diseases, Johne's disease, or any other sickness.

Environmental Measurements. Temperature and relative humidity were recorded hourly for $1 \mathrm{yr}$ inside each barn using a data logger (Hobo H8 Pro Series, temperature accuracy $\pm 0.5^{\circ} \mathrm{C}$, relative humidity accuracy $\pm 3 \%$; Hobo, Bourne, MA) located centrally in the $\mathrm{CB}$ and NV barns. Cross-ventilated barns had a logger placed in a pen closest to the air intake side and another one in a pen closest to the exhaust fans. Data loggers were positioned approximately $2.5 \mathrm{~m}$ above the bedding surface. One exhaust area data logger from a CV barn was lost and data from only 3 mo of the year were collected from that logger. Hourly outside temperature and relative humidity were collected from the weather station nearest to each barn (South Dakota Climate and Weather, http://climate.sdstate.edu/ airport/surface/archive.asp). The equation used to calculate the temperature-humidity index (THI) was as follows: $\mathrm{THI}=\mathrm{td}-(0.55-0.55 \mathrm{RH})(\mathrm{td}-58)$, where td is the dry bulb temperature in ${ }^{\circ} \mathrm{F}$ and $\mathrm{RH}$ is relative humidity expressed as a decimal (West et al., 2003).

\section{Statistical Analysis}

The MEANS procedure (SAS Institute Inc., Cary, $\mathrm{NC}$ ) was used to describe average housing system measurements, such as herd size, DIM, parity, 305-d mature equivalent yield (305ME), SCC, stocking density, pack density, and average pen size. The FREQ procedure (SAS Institute Inc.) was used to determine counts of experimental units by parity and stage of lactation. A univariate linear model was used to identify variables to be included in the multivariate mixed model. Variables with $P$-value $<0.3$ were used. A linear mixed model (MIXED procedure, SAS Institute Inc.) was built to evaluate the association between housing system and the outcome variables: lameness prevalence, hock lesion prevalence, BCS, hygiene score, CCI, SUI, mortality rate, turnover rate, respiration rates, and mastitis infection prevalence. Housing type was the forced fixed explanatory variable used in all models. Fixed explanatory covariates included in the models were season, average pen parity, average pen DIM, and average pen milk yield. The model for lameness, CCI, and SUI also included stocking density and stall dimensions as explanatory covariates. The model for respiration rates also included outside THI. Two-way interactions tested included housing system by season, housing system by parity, and housing system by DIM. Pen parity was categorized into 2 groups: primiparous, when average pen parity was $\leq 1.5$ lactations; and multiparous, when average pen parity was $>1.5$ lactations. Days in milk was categorized into 3 groups: pen average less than or equal to 30 DIM ( $\leq 30$ DIM), between 31 and 149 DIM ( $>30$ DIM $<150)$, and greater than or equal to 150 DIM ( $\geq 150 \mathrm{DIM})$. Three categories were used for outside barn THI: THI $<70$, THI $\geq 70 \leq 78$, and THI $>78$. Farm was used as random variable with pen within farm as the experimental unit. In the respiration rate model, farm was used as a random variable with animal within farm as the experimental unit. Backward stepwise elimination was used to build the model until the remaining variables included were significant at $P$ $<0.05$. Tukey-Kramer adjustment was used for multiple comparisons of least squares means in categorically distributed variables. Normality and homogeneity of variance were visually evaluated using residual plots. Those variables that were deemed nonnormal were arcsine-transformed for analysis and back-transformed with the $95 \%$ confidence interval for interpretation.

\section{RESULTS AND DISCUSSION}

Farm selection was based on willingness to participate, use of the housing system for at least $1 \mathrm{yr}$ before the beginning of the study, and preference for farms that used DHIA testing. Two CV barns and $1 \mathrm{NV}$ barn were not members of DHIA. Farms were located in southeast, southwest, and central Minnesota, and in eastern South Dakota. The mean number of lactating animals on each farm ranged from 75 to 214,399 to 1,564, and 394 to 1,552 for $\mathrm{CB}, \mathrm{CV}$, and NV barns, respectively. Lactating herd size was $121,1,000$, and 825 cows for $\mathrm{CB}, \mathrm{CV}$, and NV barns, respectively. Approximately 11,400 cows were scored each season across all farms. Milk production for the 15 herds on DHIA was $34.7,37.5$, and $37.1 \mathrm{~kg}$ of $\mathrm{FCM} /$ cow per day for $\mathrm{CB}, \mathrm{CV}$, and NV barns, respectively. Estimated 305ME production was 11,154,11,536, and 11,236 $\mathrm{kg}$ for $\mathrm{CB}$, $\mathrm{CV}$, and NV, respectively.

The numbers of experimental units by parity and stage of lactation among the 3 housing systems are shown in Table 2. Compost-bedded barns were smaller operations with primarily with only 1 pen, which was a mixed pen of parities and stages of lactation. Only 2 CB farms had more than 1 pen. One CB farm had 4 pens and separated primiparous from multiparous animals. Another CB farm had 2 pens, but was reported as 1 pen in DHIA records, and therefore scores had to be combined. Overall, the study included fewer primiparous pens than multiparous pens. Only $1 \mathrm{CB}$ contributed to the primiparous counts. Stage of lactation had a similar pattern, with most CB pens included in DIM $\geq 150$ due to the single mixed pen. This was a limitation of the study design and the reason we conducted a separate statistical analysis for lameness and hock lesions that included only CV and NV barns. 
Table 2. Distribution of experimental units by parity and stage of lactation, and mean pen size (no. of cows) for compost bedded pack (CB), cross-ventilated freestall (CV), and naturally ventilated freestall (NV) barns in Minnesota and eastern South Dakota

\begin{tabular}{lcccc}
\hline & \multicolumn{3}{c}{ Housing system } & \\
\cline { 2 - 4 } Item & $\mathrm{CB}$ & $\mathrm{CV}$ & $\mathrm{NV}$ & Total \\
\hline Experimental units (pens) & 36 & 173 & 158 & 367 \\
Parity & 4 & 43 & 40 & 87 \\
$\quad$ Primiparous & 32 & 130 & 124 & 286 \\
$\quad$ Multiparous & 0 & 12 & 18 & 30 \\
Stage of lactation & 2 & 47 & 44 & 93 \\
$\quad$ DIM $\leq 30$ & 34 & 114 & 102 & 250 \\
$>30$ DIM $<150$ & & & & Overall \\
DIM $\geq 150$ & 78.8 & 139.6 & 126.7 & 128.0 \\
Pen size (no. of cows) & 32.4 & 63.4 & 79.4 & 70.6 \\
Mean & $44-148$ & $22-269$ & $14-336$ & $14-336$ \\
SD & & & & \\
Range & & & \\
\hline
\end{tabular}

\section{Lameness}

The final model for lameness prevalence included housing system, season, parity, and housing system $\times$ parity interaction. Lameness prevalence was lower in $\mathrm{CB}$ (4.4\%) than in CV $(13.1 \% ; P=0.01)$ and NV $(15.9 \% ; P$ $<0.001)$ barns. Lameness prevalence did not differ between CV and NV barns. These results for CV and NV were similar to $17.1 \%$ for sand-based freestalls (Espejo et al., 2006) and 7.8\% for CB barns in Minnesota (Barberg et al., 2007b). Lameness prevalence by pens ranged from 0 to $43.3 \%, 2.1$ to $45.9 \%$, and 1.3 to $45.8 \%$ in CB, $\mathrm{CV}$, and NV barns, respectively. We hypothesize that CB barns had lower lameness prevalence because cows in that system spend less time standing on concrete and do not have restrictions when lying or rising.

Lameness prevalence increased as parity increased. Primiparous pens had lower prevalence of lameness than multiparous pens $(6.4$ vs. $15.5 \% ; P<0.001$, respectively). A housing system by parity interaction was found (Table 3): lameness prevalence was greater for multiparous pens housed in NV barns than for multiparous pens in $\mathrm{CB}$ barns $(P=0.016)$. Lameness prevalence did not differ for multiparous pens in NV and CV barns. When examining the primiparous pens, $\mathrm{CB}$ barns had lower lameness prevalence than CV and NV barns $(P=0.013$ and $P=0.024$, respectively). Espejo et al. (2006) also reported a significant association between lameness prevalence and parity.

Prevalence of lameness in winter, spring, summer, and fall was 14.0, 12.2, 8.0, and 8.4\%, respectively. Lameness prevalence was greater in winter than in spring, summer, and fall $(P<0.001, P=0.026$, and $P<0.001$, respectively). Spring lameness prevalence was greater than that in summer and fall $(P<0.001)$. Lameness prevalence did not differ between summer and fall. We observed during our winter visit that footbaths were not being used because of freezing conditions. Cook (2003) scored cows for lameness during the summer and winter and saw a similar pattern of higher lameness prevalence during the winter in the Midwest.

Producers were asked in a questionnaire what percentage of their herd was lame at any given time. The mean prevalence given by producers was $4.1 \%$ (with a range of 1 to $17 \%$ ), which was 3.6 times less than our estimate of overall lameness prevalence (14.9\%). These results were similar to those (3.1 times) previously reported by Espejo et al. (2006).

Table 3. Least squares means and $95 \%$ confidence interval of lameness prevalence (\%) by parity in 3 housing systems: compost-bedded pack $(\mathrm{CB})$, cross-ventilated freestall $(\mathrm{CV})$, and naturally ventilated freestall $(\mathrm{NV})$ barns in Minnesota and eastern South Dakota

\begin{tabular}{|c|c|c|c|c|c|c|}
\hline \multirow[b]{3}{*}{ Parity } & \multicolumn{6}{|c|}{ Housing system } \\
\hline & \multicolumn{2}{|c|}{$\mathrm{CB}$} & \multicolumn{2}{|c|}{$\mathrm{CV}$} & \multicolumn{2}{|c|}{$\mathrm{NV}$} \\
\hline & LSM & $95 \%$ CI & LSM & $95 \%$ CI & LSM & $95 \%$ CI \\
\hline Primiparous & $0.6^{\mathrm{b}, \mathrm{y}}$ & $0.5-5.1$ & $11.9^{\mathrm{x}}$ & $8.1-16.2$ & $10.8^{\mathrm{b}, \mathrm{x}}$ & $7.2-14.9$ \\
\hline Multiparous & $11.2^{\mathrm{a}, \mathrm{y}}$ & $7.2-15.8$ & $14.3^{\mathrm{xy}}$ & $10.7-18.4$ & $21.8^{\mathrm{a}, \mathrm{x}}$ & $17.5-26.5$ \\
\hline
\end{tabular}


Table 4. Least squares means and $95 \%$ confidence interval of severe lameness (locomotion score $\geq 4$ ) prevalence in 3 housing systems: compost-bedded pack (CB), cross-ventilated freestall (CV), and naturally ventilated freestall (NV) barns in Minnesota and eastern South Dakota

\begin{tabular}{|c|c|c|c|c|c|c|}
\hline \multirow[b]{3}{*}{ Parity } & \multicolumn{6}{|c|}{ Housing system } \\
\hline & \multicolumn{2}{|c|}{$\mathrm{CB}$} & \multicolumn{2}{|c|}{$\mathrm{CV}$} & \multicolumn{2}{|c|}{ NV } \\
\hline & LSM & $95 \%$ CI & LSM & $95 \%$ CI & LSM & $95 \%$ CI \\
\hline Primiparous & 0.4 & $0.3-3.4$ & 0.7 & $0.1-2.1$ & $0.5^{\mathrm{b}}$ & $0.0-1.5$ \\
\hline Multiparous & 1.4 & $0.3-3.1$ & 1.3 & $0.4-2.7$ & $2.7^{\mathrm{a}}$ & $1.4-4.5$ \\
\hline
\end{tabular}

${ }^{\mathrm{a}, \mathrm{b}}$ Significant between rows within housing system $(P<0.05)$.

Lameness Analysis Without CB. Because CV and NV barns were more similar in size and pen design, a separate analysis without the inclusion of CB barns was also performed. The final model for lameness prevalence without CB barns included housing system, season, parity, neck rail height, and housing system by parity interaction. Lameness prevalence was 13.4 and $14.7 \%$ in CV and NV barns, respectively. Winter, spring, summer, and fall lameness prevalence was 18.0, 16.1, 11.1 , and $11.4 \%$, respectively. Prevalence of lameness in summer and fall was lower than that in both winter and spring $(P<0.001)$. Prevalence of lameness did not differ between summer and fall or between winter and spring. Of the freestall measurements taken, only neck rail height was associated with lameness prevalence. Each 1-cm increase in neck rail height was associated with a $0.0002 \%$ increase in lameness prevalence. We hypothesize that stalls with more bedding might be more comfortable; however, the estimated difference was very small. An interaction was found between parity and housing system. Multiparous pens had a lameness prevalence of 14.5 and $20.1 \%$ in $\mathrm{CV}$ and NV barns, respectively $(P<0.001)$. Lameness prevalence did not differ for primiparous pens and averaged 12.3 and $10.0 \%$ for CV and NV barns, respectively. Multiparous pens had greater lameness prevalence than primiparous pens in NV barns $(P<0.001)$. Lameness prevalence did not differ between primiparous and multiparous pens in CV barns.

Severe Lameness. The final model for severe lameness included housing system, season, parity, DIM, milk yield, and housing system $\times$ parity interaction. The 3 housing systems did not differ for severe lameness prevalence. Severe lameness prevalence (LS $\geq 4$ ) was $0.8,1.0$, and $1.4 \%$ for $\mathrm{CB}, \mathrm{CV}$, and $\mathrm{NV}$ barns, respectively. Multiparous pens had greater lameness prevalence than primiparous pens (1.7 vs. $0.5 \% ; P=$ 0.006 ). A system $\times$ parity interaction (Table 4 ) was found: multiparous pens had greater severe lameness prevalence than primiparous pens in NV barns $(P<$ 0.001). Housing systems or parity did not differ in CV and CB barns. A greater prevalence of severe lameness was found in winter (2.6\%) than in spring, summer, and fall $(0.8,0.5$, and $0.9 \%$, respectively; $P<0.001)$. Severe lameness prevalence did not differ among spring, summer, and fall. Differences were found in severe lameness prevalence by stage of lactation. Pens $\leq 30$ DIM had lower severe lameness prevalence $(0.3 \%)$ than pens $>30$ DIM $<150(1.8 \% ; P=0.001)$ and $\geq 150$ DIM $(1.3 \% ; P$ $=0.026)$; severe lameness in the $>30$ DIM $<150$ and $\geq 150$ DIM pens did not differ. Rowlands et al. (1985) noted that lameness incidence was greatest during the first 3 mo of lactation. A strong association between sole disorders and the period between 60 and 120 DIM was observed by Vaarst et al. (1998).

\section{Hock Lesions}

The final model for HL prevalence ( $\mathrm{HL} \geq 2$ ) included housing system, season, parity, DIM, and housing system $\times$ parity interaction. Compost-bedded barns had lower prevalence of HL $(3.8 \%)$ than $\mathrm{CV}$ and NV barns $(31.2 \%$ and $23.9 \%$, respectively; $P<0.001$; Table 5$)$, with no differences between CV and NV barns. Results for the CV barns were slightly higher than the $25 \%$ prevalence reported by Fulwider et al. (2007) for sandbased freestalls. Barberg et al. (2007b) reported a higher $(24.1 \%)$ hock lesion prevalence for CB barns. Those authors hypothesized that hock lesions were present or recovering from previous housing. The soft surface in CB barns is possibly more forgiving and reduces friction compared with sand-bedded freestalls. In the current study, average pen prevalence ranged from 0 to $29.1 \%$, 2.2 to $72.4 \%$, and 0 to $67.9 \%$ in CB, CV, and NV barns, respectively. Hock lesion prevalence was greater during the spring and summer months. Although a seasonal relationship was observed for hock lesion prevalence, this could be due to hair losses being typically covered by longer hair during the colder months. Multiparous pens had more lesions than primiparous pens $(P<0.001)$. Kielland et al. (2009) reported greater odds ratio for hock lesions in multiparous animals compared with primiparous animals. Multiparous animals may have more lesions from being exposed to abrasive surfaces longer than primiparous animals or may have permanent scar tissue from a previous insult. 
Table 5. Least squares means and $95 \%$ confidence interval of hock lesion and severe hock lesion prevalence $(\%)$ in 3 housing systems: compost-bedded pack (CB), cross-ventilated freestall (CV), and naturally ventilated freestall (NV) barns in Minnesota and eastern South Dakota

\begin{tabular}{|c|c|c|c|c|}
\hline \multirow[b]{2}{*}{ Item } & \multicolumn{2}{|c|}{ Hock lesions $\geq 2$} & \multicolumn{2}{|c|}{ Hock lesion $=3$} \\
\hline & LSM & $95 \% \mathrm{CI}$ & LSM & $95 \% \mathrm{CI}$ \\
\hline \multicolumn{5}{|l|}{ Housing } \\
\hline CB & $3.8^{\mathrm{b}}$ & $0.4-10.3$ & $1.0^{\mathrm{b}}$ & $0.0-3.7$ \\
\hline $\mathrm{CV}$ & $31.2^{\mathrm{a}}$ & $21.6-41.4$ & $6.5^{\mathrm{a}}$ & $3.4-10.5$ \\
\hline NV & $23.9^{\mathrm{a}}$ & $15.4-33.6$ & $6.3^{\mathrm{a}}$ & $3.3-10.2$ \\
\hline \multicolumn{5}{|l|}{ Season } \\
\hline Winter & $13.6^{\mathrm{e}}$ & $9.1-18.8$ & $3.0^{\mathrm{d}}$ & $1.6-4.9$ \\
\hline Spring & $18.7^{\mathrm{d}}$ & $13.6-24.5$ & $4.9^{\mathrm{c}}$ & $3.0-7.3$ \\
\hline Summer & $23.7^{\mathrm{c}}$ & $18.0-30.0$ & $5.4^{\mathrm{c}}$ & $3.4-7.8$ \\
\hline Fall & $14.9^{\mathrm{e}}$ & $10.3-20.2$ & $3.3^{\mathrm{d}}$ & $1.8-5.2$ \\
\hline \multicolumn{5}{|l|}{ Parity } \\
\hline Primiparous & $13.1^{\mathrm{g}}$ & $8.2-19.0$ & $3.3^{\mathrm{g}}$ & $1.6-5.7$ \\
\hline Multiparous & $22.5^{\mathrm{f}}$ & $17.4-28.1$ & $5.0^{\mathrm{f}}$ & $3.2-7.0$ \\
\hline \multicolumn{5}{|l|}{ Stage of lactation } \\
\hline $\mathrm{DIM} \leq 30$ & $14.6^{\mathrm{i}}$ & $9.5-20.6$ & $2.6^{\mathrm{i}}$ & $1.1-4.8$ \\
\hline$>30$ DIM $<150$ & $16.4^{\mathrm{i}}$ & $11.6-22.0$ & $3.9^{\mathrm{i}}$ & $2.2-6.1$ \\
\hline DIM $>150$ & $21.9^{\mathrm{h}}$ & $16.7-27.7$ & $6.1^{\mathrm{h}}$ & $4.1-8.4$ \\
\hline
\end{tabular}

$\overline{\mathrm{a}, \mathrm{b}}$ Significant among rows (housing; $P<0.05$ ).

${ }^{\mathrm{c} \text { e }}$ Significant among rows (season; $P<0.05$ ).

${ }^{\mathrm{f}, \mathrm{g}}$ Significant between rows (parity; $P<0.05$ ).

h,i Significant among rows (stage of lactation; $P<0.05$ ).

A housing system by parity interaction was observed. Multiparous pens in CB (10.3\%) and NV (29.2\%) barns had greater hock lesion prevalence than primiparous pens $(0.4 \% ; P=0.003$ and $19.0 \% ; P<0.001$, respectively). Multiparous (30.5\%) and primiparous (31.6\%) pens in CV barns did not differ. Multiparous pens in $\mathrm{CB}$ barns had a lower prevalence of hock lesions than multiparous pens in $\mathrm{CV}$ and $\mathrm{NV}$ barns $(P=0.016$ and $P=0.029$, respectively). Primiparous pens in CB barns had lower prevalence of hock lesions than primiparous pens in CV and NV barns $(P<0.001$ and $P=0.004)$; $\mathrm{CV}$ and NV barns did not differ from one another.

Hock Lesion Prevalence Without CB. The final model for hock lesion prevalence excluding CB barns included housing system, season, DIM, parity, housing system $\times$ season interaction, and housing system by parity interaction. Hock lesion prevalence was 31.4 and $24.1 \%$ for $\mathrm{CV}$ and $\mathrm{NV}$, respectively, and not statistically different. Winter, spring, summer, and fall HL prevalence was $23.2,29.0,34.7$, and $24.3 \%$, respectively. Hock lesion prevalence increased throughout lactation and was 24.5, 25.8, and $33 \%$ for $\leq 30 \mathrm{DIM},>30$ DIM $<150$, and $\geq 150$ DIM, respectively. Prevalence in $\leq 30$ DIM and $>30$ DIM $<150$ pens did not differ. Both $\leq 30 \mathrm{DIM}$ and $>30$ DIM $<150$ had lower prevalence than $\geq 150$ DIM $(P=0.001$ and $P<0.001$, respectively). An interaction was found between housing system and parity. Multiparous animals had hock lesion prevalence of 30.9 and $29.6 \%$, and primiparous animals 31.9 and $19 \%$ in $\mathrm{CV}$ and $\mathrm{NV}$ barns, respectively. Multiparous cows had greater HL prevalence than primiparous animals in NV barns $(P<0.001)$. No other comparisons of housing system and parity were significant. A housing system by season interaction was detected. Prevalence of HL in winter, spring, summer, and fall was 25.1, 35.0, 32.2, and 28.7 in CV and 21.4, 23.4, 32.2, and 20.1 in NV barns, respectively. Prevalence of HL in summer was greater than that in winter, spring, and fall in NV barns $(P<0.001)$. Prevalence of HL did not differ between winter, spring, and fall in NV barns. Spring prevalence was greater than fall and winter prevalence in $\mathrm{CV}$ barns $(P=0.002$ and $P<0.001$, respectively). Summer prevalence was greater than fall and winter in $\mathrm{CV}$ barns $(P<0.001)$. Prevalence did not differ between spring and summer or fall and winter in $\mathrm{CV}$ barns.

Severe Hock Lesions. The final model for severe HL included housing system, season, parity, DIM, and housing system $\times$ parity interaction. Severe HL prevalence $(\mathrm{HL}=3)$ was $1.0,6.5$, and $6.3 \%$ for $\mathrm{CB}, \mathrm{CV}$, and NV barns, respectively (Table 5). Fulwider et al. (2007) and Lombard et al. (2010) reported 2.5 and $0.7 \%$, respectively, for severe HL prevalence for sand-bedded freestalls. An interaction was found between housing system and parity. Prevalence of severe HL in primiparous pens was $0.8,6.1$, and $4.4 \%$ in $\mathrm{CB}, \mathrm{CV}$, and $\mathrm{NV}$ barns, respectively. In multiparous pens, severe HL prevalence was $1.3,6.9$, and $8.5 \%$ in $\mathrm{CB}, \mathrm{CV}$, and $\mathrm{NV}$ barns, respectively. Multiparous pens in CB barns had a lower prevalence than multiparous pens in NV barns $(P=0.009)$ with a trend for CV barns $(P=0.051)$. Severe HL prevalence for multiparous pens did not dif- 
fer in CV and NV barns. Severe HL prevalence did not differ among the housing systems for primiparous pens. The only difference observed between primiparous and multiparous pens was in NV barns $(P<0.001)$. Severe HL prevalence was lower in fall than in spring and summer $(P=0.002$ and $P<0.001$, respectively $)$ and was not different in winter. Severe HL prevalence in winter was lower than that in spring and summer $(P<$ 0.001). Severe HL prevalence in spring and summer did not differ. Pens that were $\leq 30 \mathrm{DIM}$ had a prevalence of $2.6 \%$, pens $>30$ DIM $<150,3.9 \%$, and pens $\geq 150$ DIM, $6.1 \%$. Pens $\leq 30$ DIM and pens $>30$ DIM $<150$ had lower prevalence than pens $\geq 150$ DIM $(P<0.001$ and $P<0.001$, respectively), with no differences between $\leq 30 \mathrm{DIM}$ and $>30$ DIM $<150$.

\section{Hygiene}

The final model for hygiene included housing system, season, DIM, and housing system $\times$ season interaction. Mean hygiene scores were 3.18, 2.83, and 2.77 for $\mathrm{CB}$, CV, and NV barns, respectively. The CB barns had higher overall hygiene scores than CV and NV barns ( $P=0.024$ and $P=0.010$, respectively). Seasonal hygiene scores were 2.94, 2.76, 3.03, and 2.97 for winter, spring, summer, and fall, respectively. Spring hygiene scores were lower than those in winter $(P=0.003)$, summer $(P<0.001)$, and fall $(P<0.001)$. A housing system $\times$ season interaction was observed (Table 6 ). The CB barns had higher hygiene scores in the winter than the $\mathrm{CV}$ and $\mathrm{NV}$ barns $(P=0.007$ and $P=$ 0.029 , respectively); however, no differences were found among systems in the other seasons. During winter, it was more difficult for the producers in CB barns to manage the pack and keep the surface dry. Hygiene scores in CV barns varied across seasons. Summer hygiene scores were significantly higher than winter and spring scores. Hygiene scores did not differ among winter, spring, and fall measurements in the CV barns. Hygiene scores improved throughout lactation. Scores were $3.01,2.95$, and $2.82(\mathrm{SE}=0.08)$ for $\leq 30 \mathrm{DIM},>30$ DIM $<150$, and $\geq 150$ DIM, respectively. Pens $\leq 30$ DIM and $>30$ DIM $<150$ had greater hygiene scores than pens $\geq 150$ DIM $(P=0.004$ and $P=0.018)$, with no differences between the early lactation groups. Barberg et al. (2007b) reported an average hygiene score of 2.66 in CB barns during the summer. Fulwider et al. (2007) reported that cows on mattresses or waterbeds were cleaner than cows on sand-bedded freestalls, and noted that CB barns had similar hygiene scores to waterbedhoused cows.

\section{Body Condition}

The final model for body condition included housing system, season, parity, DIM, and milk yield. No differences in BCS were found among housing systems (Table 7). Seasonally, BCS scores were higher in the winter than in summer and fall $(P<0.001)$ with no differences between spring and winter. Spring BCS were greater than summer BCS $(P<0.001)$. Multiparous pens had greater BCS than primiparous pens $(P<$ 0.001). Domecq et al. (1997) reported that primiparous animals maintained a greater BCS than multiparous animals in the first 120 DIM. Contrary to those results, primiparous pens in the current study had lower BCS than multiparous pens. Pens $\leq 30$ DIM had lower BCS than pens $\geq 150$ DIM $(P<0.001)$. Pens $>30$ DIM $<150$ had a trend for lower BCS than pens $\leq 30$ DIM and lower BCS than pens $\geq 150$ DIM $(P=0.068$ and $P<$ 0.001 , respectively). Each additional kilogram of milk yield was associated with a reduction in BCS of $0.1 \%$ $(P<0.001)$.

\section{$\mathrm{CCl}$ and SUI}

The CCI and SUI were used as indicators of how comfortable the stalls appeared to be to the cows, rather than an index to estimate lying behavior. Ito et al. (2009) found no association between CCI or SUI

Table 6. Least squares means and standard error of hygiene scores in 3 housing systems: compost-bedded pack (CB), cross-ventilated freestall (CV), and naturally ventilated freestall (NV) barns in Minnesota and eastern South Dakota

\begin{tabular}{|c|c|c|c|c|c|c|}
\hline \multirow[b]{3}{*}{ Season } & \multicolumn{6}{|c|}{ Housing system } \\
\hline & \multicolumn{2}{|c|}{$\mathrm{CB}$} & \multicolumn{2}{|c|}{$\mathrm{CV}$} & \multicolumn{2}{|c|}{ NV } \\
\hline & LSM & SE & LSM & $\mathrm{SE}$ & LSM & $\mathrm{SE}$ \\
\hline Winter & $3.33^{\mathrm{a}}$ & 0.13 & $2.71^{\mathrm{b}, \mathrm{y}}$ & 0.09 & $2.78^{\mathrm{b}}$ & 0.09 \\
\hline Spring & 2.95 & 0.13 & $2.67^{\mathrm{y}}$ & 0.09 & 2.66 & 0.09 \\
\hline Summer & 3.21 & 0.13 & $3.05^{\mathrm{x}}$ & 0.09 & 2.84 & 0.09 \\
\hline Fall & 3.22 & 0.13 & $2.87^{\mathrm{xy}}$ & 0.09 & 2.82 & 0.09 \\
\hline
\end{tabular}

$\overline{\mathrm{a}, \mathrm{b}}$ Significant differences among columns (housing systems) within season $(P<0.05)$.

${ }^{\mathrm{x}, \mathrm{y}}$ Significant differences among rows (season) within housing system $(P<0.05)$. 
Table 7. Least squares means and standard error of BCS in 3 housing systems: compost-bedded pack (CB), cross-ventilated freestall (CV), and naturally ventilated freestall (NV) barns in Minnesota and eastern South Dakota

\begin{tabular}{lccc}
\hline & \multicolumn{2}{c}{ BCS } & \\
\cline { 2 - 3 } Item & LSM & SE & \\
\hline Housing & 2.91 & 0.03 & \\
CB & 2.97 & 0.03 & \\
CV & 2.96 & 0.02 & \\
NV & & & \\
Season & $2.99^{\mathrm{a}}$ & 0.02 & \\
Winter & $2.97^{\mathrm{a}}$ & 0.02 & \\
Spring & $2.91^{\mathrm{b}}$ & 0.02 & \\
Summer & $2.92^{\mathrm{b}}$ & 0.02 & \\
Fall & & & \\
Parity & $2.91^{\mathrm{d}}$ & 0.02 & \\
Primiparous & $2.98^{\mathrm{c}}$ & 0.01 & \\
Multiparous & & & \\
Stage of lactation & $2.87^{\mathrm{g}}$ & 0.03 & \\
DIM $\leq 30$ & $2.93^{\mathrm{f}}$ & 0.02 & \\
$>30$ DIM $<150$ & $3.04^{\mathrm{e}}$ & 0.02 & \\
DIM $\geq 150$ & Estimate & SE & \\
\cline { 2 - 3 } & -0.01 & 0.001 & $<0.001$ \\
Milk (kg) & &
\end{tabular}

${ }^{\mathrm{a}, \mathrm{b}}$ Significant among rows within season $(P<0.05)$.

${ }^{\mathrm{c}, \mathrm{d}}$ Significant between rows within parity $(P<0.05)$.

${ }^{\mathrm{e} g}$ Significant among rows within DIM $(P<0.05)$.

measured only once per visit ( $2 \mathrm{~h}$ after milking) at the pen level and the mean daily lying time of focal cows in 43 herds. Cows change their lying behavior when THI $>68$ (Cook et al., 2007). Therefore, we attempted to evaluate whether the environment in $\mathrm{CV}$ barns would potentially result in stalls being more comfortable to cows, which could be related to lower THI in the barn and the absence of flies.

The final model for CCI included housing type, season, DIM, and housing system $\times$ season interaction. A trend was observed for NV barns to have a lower CCI than CV barns ( 81.4 vs. $85.9 ; P=0.08)$. An interaction was found between housing system and season. The NV barns had lower CCI during the summer than the CV barns (76.3 vs. 84.6; $P<0.002$ ). Cow comfort index did not differ between CV and NV barns in winter, spring, or fall. Cow comfort index was lower in summer (80.5) than in winter $(85.2 ; P<0.009)$, spring $(85.2 ; P$ $<0.001)$, and fall (83.9; $P<0.001)$; CCI did not differ between winter, spring, and fall. Pens $\geq 150$ DIM had greater CCI than pens $\leq 30 \mathrm{DIM}(87.5$ vs. $79.4 ; P<$ $0.001)$ and pens $>30 \mathrm{DIM}<150(84.2 ; P=0.013)$. Pens $>30$ DIM $<150$ had greater CCI than pens $\leq 30$ DIM $(P=0.012)$. Nelson (1996) recommended that CCI be at least $80 \%$ and ideally greater than $85 \%$ as an indication of good stall comfort. The CV barns and 3 of the seasonal averages were near the recommended percentage. The NV barns had CCI 3.6 percentage units lower than the recommended $85 \%$; however, the current results were higher than the previously reported $76 \%$ with mattress stalls (Cook et al., 2005). Krawczel et al. (2008) reported CCI between 85 and $86 \%$ on mattress freestalls with pen stocking densities from 100 to $131 \%$.

The final model for SUI included housing system, season, stocking density, and housing system by season interaction. Recommended SUI is greater than $75 \%$ (Overton et al., 2003). The NV barns had a lower SUI (71.5) than $\mathrm{CV}$ barns $(76.8 ; P=0.037)$. Cook et al. (2005) observed a SUI of $76.3 \%$ in sand-bedded stalls, which was slightly higher than observed in the current study with NV barns. Mattress freestalls with a stocking density of 100,113 , and $131 \%$ had SUI of $80.3,79.5$, and $74.8 \%$ (Krawczel et al., 2008). Stocking density was associated with SUI. Each 1-unit increase in stocking density increased the SUI by $0.13 \%(P<0.001)$. We do not understand this relationship very well, but cows may place a priority on lying down at higher stocking densities and might use the stalls more. It would have been helpful to have bedding depth measurements and coordinate our visits with the time of bedding addition, but this was not logistically possible. A housing system $\times$ season interaction was detected. Similar to the results of CCI, SUI was lower in NV barns than CV barns during the summer (65.4 vs. 75.2 , respectively; $P=$ 0.01 ), and SUI during the winter, spring, or fall did not differ in NV and CV barns. Stall usage index was lower in summer (70.3) than in spring $(75.7 ; P=0.003)$, fall (75.7; $P<0.001)$, and winter $(74.9 ; P=0.024)$.

\section{Respiration Rates}

Vitali et al. (2009) observed increased mortality rates when the THI was 70, and Cook et al. (2007) noted that behavioral changes occurred when the THI reached 68. In the current study, we used a THI of 70 as the onset of heat stress. Mild to moderate heat stress was classified as THI $\geq 70 \leq 78$ and severe heat stress as THI $>78$. Twenty-seven percent of the respiration rate measurements were taken when THI $<70$, $66.5 \%$ when $\mathrm{THI} \geq 70 \leq 78$, and $6.4 \%$ when $\mathrm{THI}>78$. Approximately $75 \%$ of the measurements were taken under some degree of heat stress.

The final model for respiration rates included housing system, milk yield, and outside THI. Respiration rates were $58.4,57.5$, and 59.3 breaths/min in $\mathrm{CB}, \mathrm{CV}$, and NV barns, respectively, and they were not significantly different among systems. Schütz et al. (2010) reported slightly lower respiration rates (50 breaths/min) for animals that were given the option to be under a shade structure.

Respiration rates based on the 3 outside THI categories numerically increased as outside THI increased. Respiration rates were 51.9, 57.8, and 65.5 breaths/ 
min when THI $<70$, THI $\geq 70 \leq 78$, and THI $>$ 78 , respectively. Each additional kilogram of milk yield was associated with an increase in respiration rate of $0.08 \pm 0.04(P<0.001)$. Higher milk production increases a cow's susceptibility to heat stress (Nardone et al., 2006). Current results show a positive association between milk yield and respiration rates. During hot weather, dairy cows try to combat heat stress by reducing DMI, and milk production eventually decreases (Rhoads et al., 2009).

Cross-ventilated barns with evaporative cooling were built to provide a more comfortable summer environment for animals and employees. The CV barns had a 2.0- and 2.1-unit lower THI compared with $\mathrm{CB}(P=$ $0.023)$ and NV $(P=0.018)$ barns, respectively, during the summer (from June 21 to September 22). However, respiration rates were only numerically lower than $\mathrm{CB}$ and NV barns.

\section{Mastitis Prevalence}

Mastitis infection prevalence was used as an indirect measurement of welfare in this study. Cows were considered to be infected when their test-day SCC was greater than 200,000 cells/mL. Mastitis infection prevalence was $33.4,26.8$, and $26.8 \%$ for $\mathrm{CB}, \mathrm{CV}$, and $\mathrm{NV}$ barns, respectively, with no differences in prevalence among housing systems. No adjustment factors were significant in the model. Barberg et al. (2007b) reported similar infection prevalence $(27.7 \%)$ in 12 compost-bedded pack barns.

\section{Culling and Mortality}

Herd turnover rates were 30.1, 24.6, and 29.0\% in CB, $\mathrm{CV}$, and NV barns, respectively. Mortality rates were $5.1,5.8$, and $5.0 \%$ in $\mathrm{CB}, \mathrm{CV}$, and NV barns, respectively. One CV and $1 \mathrm{NV}$ barn were excluded from this analysis due to substandard on-farm records. Housing systems did not differ for herd turnover or mortality rates. Herd turnover rate for animals that left the herd less than 60 DIM were 6.0, 5.6, and $9.4 \%$ in CB, CV, and NV barns, respectively. A trend was observed for $\mathrm{NV}$ barns to have greater herd turnover than $\mathrm{CV}(P<$ $0.084)$ and $\mathrm{CB}(P=0.092)$ barns, with no differences between CB and CV. Mortality rates for animals that left the herd less than 60 DIM were 2.3, 2.5, and 2.8\% in $\mathrm{CB}, \mathrm{CV}$, and $\mathrm{NV}$, respectively. Mortality rates were similar among housing systems and lower than previous reported values of $5.9 \%$ in northern United States (Smith et al., 2000).

Herd turnover rates can have large ranges depending on the objectives of the farm owner. Farms that are expanding typically will hold on to less profitable animals to fill the barn, whereas a farm that is stable with excessive replacements may cull a greater number of their less profitable animals. Overall, the top 3 reasons for animals to be sold in the current study were sick or injured (24.4\%), breeding (20.7\%), and mastitis (16.5\%). These results were similar to those of Smith et al. (2000), with injuries or others at 25.8\% and reproduction at $17.1 \%$ in northern US farms. The top reasons for being sold in CB barns were breeding $(24.0 \%)$, mastitis $(20.2 \%)$, and sick or injured (19.3\%). The top reasons for being sold in CV barns included sick or injured (20.9\%), breeding $(18.4 \%)$, and production $(16.6 \%)$. For CV barns, $15.8 \%$ of the sold observations did not contain a remark, which could influence the percentages in each category compared with 3.1 and $3.8 \%$ of nonreported reasons in CB and NV barns, respectively. The top reasons in NV barns were sick or injured $(34.0 \%)$, breeding $(19.1 \%)$, and mastitis $(16.8 \%)$. When comparing the percentages of reasons for leaving the farm, housing systems did not differ for mastitis, production, breeding, dairy, sick or injured, or miscellaneous.

When animals were sold from the herd within the first 60 DIM, the primary reason was sick or injury $(42.8 \%)$. The next 2 causes were mastitis $(19.3 \%)$ and miscellaneous (15.9\%) reasons, which included udder conformation. Being sick or injured was the most common reported reason for leaving the herd, being 40.5, 32.9 , and $55.4 \%$ in CB, CV and NV barns, respectively. After sickness or injury, the next most common reported reason for leaving the herd was mastitis in $\mathrm{CB}$ barns $(25.8 \%)$, or miscellaneous reasons in CV $(23.6 \%)$ and NV $(24.4 \%)$ barns, respectively. The CV barns had $13.6 \%$ of the reasons not reported; if the reasons had been reported the interpretation of the results might change. In the sick or injured category, $31.4 \%$ resulted from sick animals that most likely had transition problems after calving. Lameness issues accounted for $23.7 \%$ from the sick or injured category. Lameness and transition issues are both major welfare concerns and should be minimized to prevent animal suffering.

\section{CONCLUSIONS}

Of the 3 dairy cattle housing options examined in this study, dairy cattle housed in CB barns showed reduced prevalence of lameness and hock lesion compared with CV and NV barns, with no adverse associations with body condition, respiration rates, mastitis infection prevalence, culling, or mortality. Cows in CB barns were dirtier than cows in $\mathrm{CV}$ and NV barns. The CV barns had greater CCI and SUI than NV barns in the summer, and CV barns had lower THI during the summer than NV and CB barns. Respiration rates 
were numerically lower in CV barns during the summer compared with $\mathrm{CB}$ and NV barns; however, the difference was not significant. Although cows in CB barns had better feet and leg health, as indicated by reduced prevalence of lameness and hock lesions, acquiring bedding and managing the bedded pack could limit the use of CB barns. A few differences were observed between the 2 freestall housing systems but they were relatively minor; therefore, the choice of housing system could depend on factors such as economics and preference.

\section{ACKNOWLEDGMENTS}

The authors thank the dairy producers for their participation in the study. We also thank Melisa Bauer, Amy Hazel, Ilya Salnikov, and Rose Stenglein (University of Minnesota) for help with on-farm data collection and Luis Espejo (University of Minnesota) for assistance with statistical analysis. This project was funded by the University of Minnesota Rapid Agricultural Response Fund and the Hueg-Harrison Fellowship.

\section{REFERENCES}

Barberg, A. E., M. I. Endres, and K. A. Janni. 2007a. Compost dairy barns in Minnesota: A descriptive study. J. Appl. Eng. Agric. 23:97-102.

Barberg, A. E., M. I. Endres, J. A. Salfer, and J. K. Reneau. 2007b. Performance and welfare of dairy cows in an alternative housing system in Minnesota. J. Dairy Sci. 90:1575-1583.

Cook, N. B. 2003. Prevalence of lameness among dairy cattle in Wisconsin as a function of housing type and stall surface. J. Am. Vet. Med. Assoc. 223:1324-1328.

Cook, N. B., T. B. Bennett, and K. V. Nordlund. 2005. Monitoring indices of cow comfort in free-stall-housed dairy herds. J. Dairy Sci. 88:3876-3885.

Cook, N. B., R. L. Mentink, T. B. Bennett, and K. Burgi. 2007. The effect of heat stress and lameness on time budgets of lactating dairy cows. J. Dairy Sci. 90:1674-1682.

Domecq, J. J., A. L. Skidmore, J. W. Lloyd, and J. B. Kaneene. 1997. Relationship between body condition scores and milk yield in a large dairy herd of high-yielding Holstein cows. J. Dairy Sci. 80:101-112.

Enting, H., D. Kooij, A. A. Dijkhuizen, R. B. M. Huirne, and E. N. Noordhuizen-Stassen. 1997. Economic losses due to clinical lameness in dairy cattle. Livest. Prod. Sci. 49:259-267.

Espejo, L. A., M. I. Endres, and J. A. Salfer. 2006. Prevalence of lameness in high-producing Holstein cows housed in freestall barns in Minnesota. J. Dairy Sci. 89:3052-3058.

Ferguson, J. D., D. T. Galligan, and N. Thomsen. 1994. Principal descriptors of body condition score in Holstein cows. J. Dairy Sci. $77: 2695-2703$.

Flower, F. C., and D. M. Weary. 2006. Effect of hoof pathologies on subjective assessments of dairy cow gait. J. Dairy Sci. 89:139-146.

Fulwider, W. K., T. Grandin, D. J. Garrick, T. E. Engle, W. D. Lamm, N. L. Dalsted, and B. E. Rollin. 2007. Influence of free-stall base on tarsal joint lesions and hygiene in dairy cows. J. Dairy Sci. 90:3559-3566.

Harner, J. P., J. F. Smith, M. de Haro Marti, R. Sheffield, J. Zulovich, S. Pohl, S. Pasikanti, D. Fulhage, R. Nicoli, B. Hetchler, L. Jacobson, K. Dhuyvetter, and M. J. Brouk. 2007. Characteristics of low-profile cross-ventilated freestalls. ASAE Paper No. 701P0507e in Proc. 6th Int. Dairy Housing Conf., Minneapolis, MN. ASABE, St. Joseph, MI.

Ito, K., D. M. Weary, and M. A. G. von Keyserlingk. 2009. Lying behavior: Assessing within- and between-herd variation in free-stallhoused dairy cows. J. Dairy Sci. 92:4412-4420.

Kielland, C., L. E. Ruud, A. J. Zanella, and O. Osteras. 2009. Prevalence and risk factors for skin lesions on legs of dairy cattle housed in freestalls in Norway. J. Dairy Sci. 92:5487-5496.

Krawczel, P. D., C. T. Hill, H. M. Dann, and R. J. Grant. 2008. Short communication: Effect of stocking density on indices of cow comfort. J. Dairy Sci. 91:1903-1907.

Lombard, J. E., C. B. Tucker, M. A. G. von Keyserlingk, C. A. Kopral, and D. M. Weary. 2010. Associations between cow hygiene, hock injuries, and free stall usage on US dairy farms. J. Dairy Sci. 93:4668-4676.

Nardone, A., B. Ronchi, N. Lacetera, and U. Bernabucci. 2006. Climatic effects on productive traits in livestock. Vet. Res. Commun. 30:75-81.

Nelson, A. J. 1996. On-farm nutrition diagnostics. Pages 76-85 in Proc. 29th Annu. Conf. Am. Bovine Pract., San Diego, CA. AABP, Rome, GA.

Overton, M. W., D. A. Moore, and W. M. Sischo. 2003. Comparison of commonly used indices to evaluate dairy cattle lying behavior. Pages 125-130 in Proc. 5th Int. Dairy Housing Conf., Fort Worth, TX. ASAE, St. Joseph, MI.

Reneau, J. K., A. J. Seykora, B. J. Heins, M. I. Endres, R. J. Farnsworth, and R. F. Bey. 2005. Association between hygiene scores and somatic cell scores in dairy cattle. J. Am. Vet. Med. Assoc. 227:1297-1301.

Rhoads, M. L., R. P. Rhoads, M. J. VanBaale, R. J. Collier, S. R. Sanders, W. J. Weber, B. A. Crooker, and L. H. Baumgard. 2009. Effects of heat stress and plane of nutrition on lactating Holstein cows: I. production, metabolism, and aspects of circulating somatotropin. J. Dairy Sci. 92:1986-1997.

Rowlands, G. J., A. M. Russell, and L. A. Williams. 1985. Effects of stage of lactation, month, age, origin and heart girth on lameness in dairy cattle. Vet. Rec. 117:576-580.

Ryan, D. P., M. P. Boland, E. Kopel, D. Armstrong, L. Munyakazi, R. A. Godke, and R. H. Ingraham. 1992. Evaluating two different evaporative cooling management systems for dairy cows in a hot, dry climate. J. Dairy Sci. 75:1052-1059.

Schütz, K. E., A. R. Rogers, Y. A. Poulouin, N. R. Cox, and C. B. Tucker. 2010. The amount of shade influences the behavior and physiology of dairy cattle. J. Dairy Sci. 93:125-133.

Sheffield, R., M. de Haro Marti, J. F. Smith, and J. P. Harner. 2007. Air emissions from a low-profile cross-ventilated dairy barn. In Proc. Int. Symp. Air Quality and Waste Mgmt. for Agric. ASAE Pub \#701P0907. Am. Soc. Agric. Eng., St. Joseph. MI.

Smith, J. F., and J. P. Harner. 2007. Comprehensive evaluation of a low-profile cross-ventilated freestall barn. Pages 127-147 in Proc. 7th Western Dairy Management Conf., Reno, Nevada. Accessed Nov. 15, 2010. http://www.wdmc.org/2007/WDMC\%202007.pdf.

Smith, J. W., L. O. Ely, and A. M. Chapa. 2000. Effect of region, herd size, and milk production on reasons cows leave the herd. J. Dairy Sci. 83:2980-2987.

Smith, T. R., A. Chapa, S. Willard, C. Herndon Jr., R. J. Williams, J. Crouch, T. Riley, and D. Pogue. 2006. Evaporative tunnel cooling of dairy cows in the southeast. I: Effect on body temperature and respiration rate. J. Dairy Sci. 89:3904-3914.

Vaarst, M., J. Hindhede, and C. Enevoldsen. 1998. Sole disorders in conventionally managed and organic dairy herds using different housing systems. J. Dairy Res. 65:175-186.

Vitali, A., M. Segnalini, L. Bertocchi, U. Bernabucci, A. Nardone, and N. Lacetera. 2009. Seasonal pattern of mortality and relationships between mortality and temperature-humidity index in dairy cows. J. Dairy Sci. 92:3781-3790.

West, J. W., B. G. Mullinix, and J. K. Bernard. 2003. Effects of hot humid weather on milk temperature, dry matter intake, and milk yield of lactating dairy cows. J. Dairy Sci. 86:232-242. 